\begin{tabular}{|c|c|}
\hline 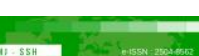 & Malaysian Journal of Social Sciences and Humanities (MJSSH) \\
\hline Malaysian Journal of & Volume 6, Issue 10, October 2021 \\
\hline (Mu-ssH) & e-ISSN : 2504-8562 \\
\hline & $\begin{array}{l}\text { Journal home page: } \\
\text { www.msocialsciences.com }\end{array}$ \\
\hline
\end{tabular}

\title{
Pengaruh Sikap, Pengetahuan dan Kemahiran Terhadap Pencapaian Kendiri Guru di Sabah
}

\author{
Sarimawathy Jumanie ${ }^{1}$, Syahrul Nizam Salam ${ }^{1}$ \\ 1Pusat Penataran Ilmu dan Bahasa (PPIB), Universiti Malaysia Sabah (UMS), Malaysia \\ Correspondence: Syahrul Nizam Salam (insantakwa@yahoo.com)
}

\begin{abstract}
Abstrak
$\overline{\text { Kajian ini bertujuan mengenal pasti pengaruh sikap, pengetahuan dan kemahiran guru Bahasa Melayu }}$ terhadap pencapaian konsep kendiri guru Bahasa Melayu di Sabah. Reka bentuk kajian menggunakan kaedah tinjauan. Soal selidik sebagai instrumen kajian telah digunakan untuk mendapatkan data kuantitatif melibatkan seramai 380 orang guru Bahasa Melayu iaitu sebagai responden. Data kajian telah dianalisis menggunakan statistik IBM SPSS versi 22. Data yang diperoleh, dianalisis menggunakan ujian statistik parametrik iaitu regresi berganda. Keputusan menunjukkan terdapat pengaruh yang signifikan faktor peramal iaitu sikap, pengetahuan dan kemahiran guru terhadap pencapaian kendiri guru Bahasa Melayu. Implikasi daripada kajian ini, mencadangkan bahawa pencapaian kendiri guru Bahasa Melayu perlu sentiasa dipertingkatkan dan ditambah baik dari segi sikap, pengetahuan dan kemahiran dalam meningkatkan pencapaian akademik di sekolah.
\end{abstract}

Kata kunci: sikap, pengetahuan, kemahiran dan pencapaian kendiri

\section{The Influence of Attitudes, Knowledge and Skills Towards Self-Achievement of Malay Language Teachers in Sabah}

\begin{abstract}
The purpose of this study is to identify the influence of attitudes, knowledge and teacher's skills towards self- achievement of Malay language teachers in Sabah. The research design is using survey method. The questionnaire as a research instrument was used to obtain quantitative data involving 380 Malay language teachers as selected respondents through random sampling. The data were analyzed using the IBM SPSS version 22 and the data obtained were analyzed and inferential analysis using parametric statistical is multiple regression. The findings showed that for multiple regression analysis, it is found that there is a significant influence of the forecasting factor ie attitude, knowledge and teachers' skills towards self-achievement of Bahasa Melayu teacher. The implication of this study suggests that the national school should be constantly enhanced and improved in term of attitude, knowledge and softskill in order to increasing the achievement of academic in school.
\end{abstract}

Keywords: knowledge, skills and self-achievement 


\section{Pengenalan}

Dalam dunia pendidikan elemen-elemen konsep kendiri dalam pembangunan masyarakat perlu dipertingkatkan dan selari dengan perkembangan pembangunan ekonomi negara dalam mendepani cabaran revolusi industri 4.0 (IR4.0). Dalam meningkatkan pencapaian kendiri sebagai agenda utama yang perlu diberi perhatian untuk menjadikan negara pusat tumpuan pendidikan dunia dan negara maju sepenuhnya perlu menilai bahawa pencapaian seseorang bukan sahaja diukur melalui gred semata-mata, malah ia jauh lebih daripada pencapaian akademik seseorang iaitu pencapaian konsep kendiri seseorang individu. Pembangunan kendiri yang dititik beratkan dalam setiap dasar kerajaan dapat menjamin kestabilan pembangunan model insan dalam aspek penerapan nilai-nilai kendiri positif yang berkait rapat dengan pendidikan, keadilan sosial, kestabilan politik, kualiti hidup, nilai sosial dan maruah bangsa serta keyakinan.

Selain itu, melalui sistem pendidikan negara menerusi PPPM 2013-2025, dengan mengambil kira pembangunan kendiri dalam kalangan warga pendidik, beberapa program dibentuk dan dilaksanakan bagi melahirkan modal insan yang bukan sahaja mempunyai kelayakan dalam pencapaian akademik tetapi memiliki sahsiah kendiri yang unggul menerusi beberapa objektif yang menjadi garis panduan KPM iaitu memahami prestasi dan cabaran semasa, mewujudkan visi dan aspirasi yang jelas serta menggariskan transformasi sistem pendidikan secara komprehensif merangkumi pembangunan modal insan yang cemerlang di sekolah termasuk guru dan murid. Salah satu cabaran yang dititikberatkan adalah pembangunan kendiri yang berorientasikan penguasaan konsep kendiri dalam yang melibatkan semua pihak seperti guru, ibu bapa dan masyarakat.

\section{Sorotan Literatur}

Dalam kajian Syahrul et al. (2018) pembangunan konsep kendiri amat penting kerana melibatkan pengetahuan serta menjadi perkembangan sikap yang baik dalam membentuk modal insan yang berkualiti. Ini kerana, persediaan yang rapi serta kaedah pengajaran dan pembelajaran yang bijak yang dibuat oleh seseorang guru serta terancang hasil daripada perkembangan kendiri positif dapat membantu menyelesaikan masalah pencapaian dalam kalangan pelajar melalui pembangunan sahsiah kendiri yang diterapkan di peringkat persekolahan seperti aspek pencapaian kendiri. Kajian Tangney, Boone dan Baumeister (2018) menunjukkan konsep kendiri yang rendah, akan menyebabkan seseorang berhadapan dengan permasalahan secara tidak langsung.

Menurut Klapp (2018) konsep kendiri yang rendah memberi kesan kepada nilai gred pencapaian dalam akademik yang menjadi kegagalan kepada proses pengajaran dan pembelajaran yang dilakukan di sekolah. Terdapat pelbagai faktor yang menghalang guru Bahasa Melayu daripada meningkatkan pencapaian keputusan seperti dalam pencapaian Kertas Penulisan UPSR iaitu terutamanya dalam penguasaan kendiri dalam menguasai kemahiran memeriksa kertas penulisan mengikut format yang standard yang perlu diselidiki. Sikap dan persepsi guru terutamanya dalam memperkembangkan ilmu kemahiran yang profesional. Menurut Kulanzsalleh (2005) peranan guru kepada diri sendiri adalah memiliki kemahiran agar dapat digunakan untuk melahirkan para pelajar yang juga pada suatu hari nanti akan menjadi sebahagian daripada tenaga kerja negara.

Perkara-perkara asas yang perlu dimiliki oleh guru untuk mengendalikan proses pengajaran dan pembelajaran dengan berkesan ialah guru tersebut haruslah memiliki ilmu pengetahuan tentang mata pelajaran yang diajar, berkemahiran untuk mengajar kandungan mata pelajaran tersebut, mempunyai sikap yang sesuai dan berkemampuan untuk menangani pelbagai cabaran yang mungkin timbul dalam proses pengajaran dan pembelajaran (Ravichandran \& Rajendran, 2007). Dengan adanya pengetahuan, pengalaman dan kemahiran dalam memeriksa kertas penulisan tersebut, secara tidak langsung akan dapat meningkatkan lagi prestasi akademik murid dalam kertas penulisan UPSR. 


\section{Kerangka Konseptual Kajian}

Kerangka konseptual adalah satu perhubungan yang dijadikan asas panduan dalam proses penyelidikan dan merupakan satu perhubungan antara variabel dalam komponen-komponen penyelidikan (Ghazali dan Sufean, 2016). Justeru dalam kajian kerangka konseptual kajian mengikut hubungan berganda 3 IV $=1 \mathrm{DV}$.

\section{Rajah 1: Kerangka Konseptual Kajian Pengaruh Pencapaian Kendiri Guru Bahasa Melayu}

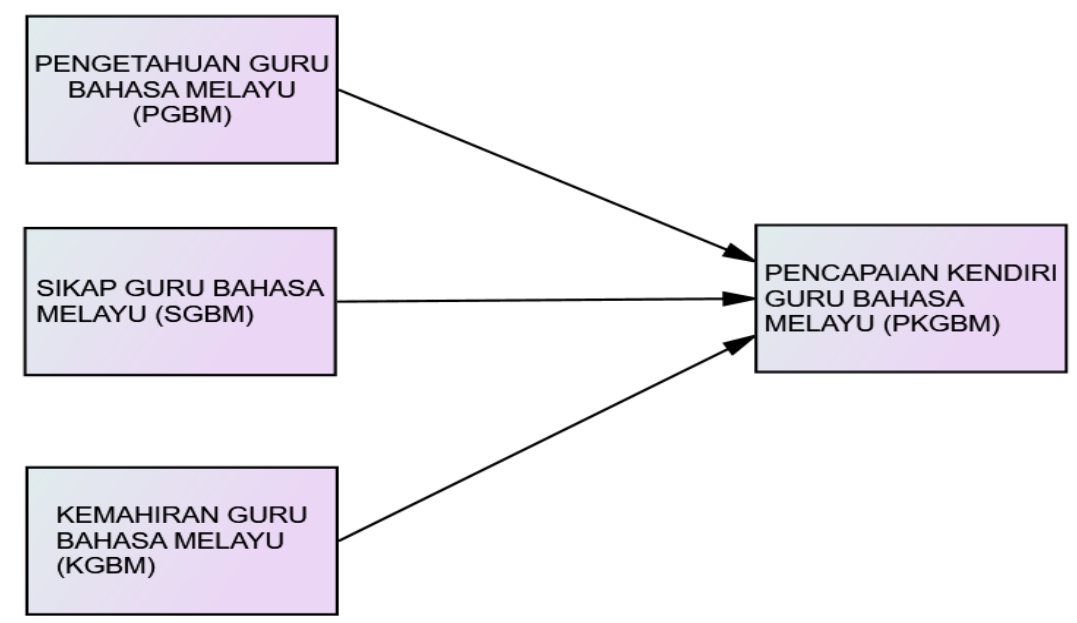

Rajah 1 menunjukkan konteks kajian kerangka konseptual yang dibangunkan berdasarkan model hubungan berganda $3 \mathrm{IV}=1 \mathrm{DV}$. Kajian selaras dengan aliran positivisme yang beranggapan setiap benda boleh diukur dan dikuantifikasi secara maksimum dan wujud dalam bentuk yang munasabah (Ghazali \& Sufean, 2016). Hubungan berganda pengetahuan, sikap dan kemahiran yang menjurus kepada pomboleh ubah bersandar iaitu pencapaian kendiri menjelaskan hubungan antara tiga pemboleh ubah bebas dengan satu pemboleh ubah bersandar kajian. Kerangka konsep ini dapat menerangkan ujian statistik yang bersesuaian bagi menentukan hubungan dan pengaruh setiap pemboleh ubah kajian yang dicadangkan melalui ujian regresi berganda.

\section{Hipotesis Kajian}

Hipotesis yang dikaji untuk melihat pengaruh dan sejauh mana pengaruh item-item peramal sikap, pengetahuan dan kemahiran terhadap konsep kendiri guru Bahasa Melayu mempunyai pengaruh antara satu sama lain. Hipotesis nol yang akan di uji adalah seperti berikut:

Ho1: Tidak terdapat pengaruh yang signifikan antara sikap guru bahasa Melayu, pengetahuan guru bahasa Melayu dan Kemahiran guru bahasa Melayu terhadap pencapaian kendiri guru bahasa Melayu

\section{Metod Kajian}

Dalam kajian ini, mengenal pasti populasi perlu dibincangkan secara rasional tentang pemilihan sampel kajian yang terlibat dalam memberikan data dan maklumat yang dikumpulkan untuk menjawab soalan kajian (Gazali \& Sufean, 2016). Menurut Cohen (2000) semua ahli dalam kelompok yang dikaji adalah populasi kajian. Dalam populasi penyelidikan ini melibatkan guru bahasa Melayu. Setelah menentukan populasi kajian, usaha dilakukan untuk menentukan teknik pensampelan dan kaedah menentukan saiz sampel bersesuaian bagi kajian ini. Menurut Chua (2006) pensampelan adalah proses untuk memilih sampel daripada populasi sebagai asas untuk meramal sesuatu fakta dan situasi daripada suatu populasi yang lebih besar. Pemilihan sampel yang sistematik perlu dilakukan supaya rumusan yang tepat di akhir 
kajian dapat dicapai dan dilakukan dengan berkesan (Mohd. Majid, 1993). Seterusnya beberapa teknik digunakan bagi mendapatkan sampel yang dapat mewakili populasi dengan tepat.

Lokasi kajian dijalankan di seluruh negeri Sabah, dengan penggunaan tiga fasa kaedah pensampelan iaitu kelompok, strata dan rawak untuk membantu penyelidik membuat kesimpulan dengan lebih tepat dan meyakinkan. Pensampelan strata, digunakan mewakili lima buah sekolah setiap zon di negeri Sabah. Suatu set parameter bagi memilih responden dalam satu set perwakilan sampel, responden dalam kajian ini telah ditetapkan secara kelompok kepada lima zon iaitu PPG Keningau (Keningau), PPG Sandakan (Sandakan), PPG Tawau (Tawau), PPG Kota Kinabalu (Kota Kinabalu) dan PPG (Lahad Datu) yang mana wakil kawasan di setiap zon dilakukan secara cabutan rawak mudah.

Saiz sampel kajian ini ditentukan berdasarkan kepada panduan teknik pensampelan Krejcie dan Morgan bagi mendapatkan sampel yang mewakili populasi dengan tepat. Berpandukan Krejcie dan Morgan (1970) menunjukkan kadar menentukan jumlah sampel daripada populasi kajian dalam lingkungan 5000 - 6000, maka saiz sampel kajian ditetapkan dalam lingkungan 357 hingga 361 dan dalam kajian ini terdapat seramai 380 responden guru Bahasa Melayu yang terlibat sekali gus menepati saranan Krejcie dan Morgan (1970) iaitu seramai 361 saiz sampel ke atas. Berdasarkan kepada jumlah guru bahasa Melayu seramai 5205 orang, maka saiz sampel kajian yang terkumpul bagi guru bahasa Melayu ( $\mathrm{n}=361$ orang) adalah memadai dengan saiz sampel wajaran bagi saiz populasi sebagaimana yang dicadangkan Krejcie dan Morgan (1970).

Reka bentuk kajian ini menggunakan pendekatan kuantitatif dan kaedah tinjauan yang bersesuaian dengan objektif kajian, saiz populasi dan sampel kajian serta kedudukan geografi kajian. Menurut Gazali dan Sufean (2016) penyelidikan kuantitatif merujuk kepada kajian yang mana dapatan dihasilkan dengan menggunakan analisis statistik dalam bentuk angka. Selain itu, penggunaan kaedah soal selidik adalah kerana kesesuaian kaedah ini digunakan untuk penggunaan efektif dalam masa kajian dijalankan Gay dan Peter (2003) dan kesan kajian, selain responden kajian (Sabitha, 2009). Menurut Ahmad Mahzan (1995) kaedah yang seragam yang dibuat memudahkan penyelidik menganalisis data dengan baik.

\section{Hasil Kajian}

Analisis regresi digunakan untuk meramal serta menerangkan nilai antara satu pemboleh ubah iaitu konsep kendiri guru bahasa Melayu dengan beberapa pemboleh ubah seperti sikap, pengetahuan dan kemahiran. Analisis yang digunakan pengkaji ini penting untuk menunjukkan sekuat mana pengaruh pemboleh ubah peramal sikap, pengetahuan dan kemahiran terhadap konsep kendiri guru bahasa Melayu Sekolah Kebangsaan. Hasil analisis dapat ditunjukkan seperti jadual 1 berikut :

Jadual 1: Analisis Ujian Stepwise Pemboleh Ubah Peramal Kajian Terhadap Pencapaian Kendiri Guru

\begin{tabular}{|c|c|c|c|}
\hline & \multicolumn{3}{|c|}{ Variables Entered/Removed ${ }^{\mathrm{a}}$} \\
\hline Model & Variable Entered & Variables Removed & Method \\
\hline 1 & $\begin{array}{l}\text { Sikap Guru Bahasa } \\
\text { Melayu }\end{array}$ & & $\begin{array}{l}\text { Stepwise (Criteria: Probability-of-Fto- } \\
\text { enter }<=.050 \text {, Probability-of-F- } \\
\text { toremove }>=.100 \text { ). }\end{array}$ \\
\hline 2 & $\begin{array}{l}\text { Pengetahuan Guru Bahasa } \\
\text { Melayu }\end{array}$ & & $\begin{array}{l}\text { Stepwise (Criteria: Probability-of-Fto- } \\
\text { enter }<=.050, \text { Probability-of-F- } \\
\text { toremove }>=.100) \text {. }\end{array}$ \\
\hline 3 & $\begin{array}{l}\text { Kemahiran Guru Bahasa } \\
\text { Melayu }\end{array}$ & & $\begin{array}{l}\text { Stepwise (Criteria: Probability-of-Fto- } \\
\text { enter }<=.050 \text {, Probability-of- } F- \\
\text { toremove }>=.100) \text {. }\end{array}$ \\
\hline
\end{tabular}


Pengkaji telah menggunakan kaedah Stepwise bagi menentukan kekuatan setiap pemboleh ubah dalam meramal pemboleh ubah bersandar kajian. Jadual 1 menunjukkan kesemua tiga pemboleh ubah peramal iaitu sikap, pengetahuan dan kemahiran dapat dimasukkan ke dalam model regresi pada aras signifikan $(\mathrm{P}<0.05)$.

Jadual 2: Analisis Ujian Regresi Pelbagai

\begin{tabular}{|c|c|c|c|c|c|c|c|c|c|}
\hline \multicolumn{9}{|c|}{ Model Summary } & \multirow[b]{2}{*}{$\begin{array}{l}\text { Sig. F } \\
\text { Change }\end{array}$} \\
\hline Model & $\mathbf{R}$ & $\begin{array}{l}\text { R } \\
\text { Square }\end{array}$ & $\begin{array}{l}\text { Adjusted } \\
\mathbf{R} \\
\text { Square }\end{array}$ & $\begin{array}{l}\text { Std. Error } \\
\text { of the } \\
\text { Estimate }\end{array}$ & $\begin{array}{l}\text { R Square } \\
\text { Change }\end{array}$ & $\begin{array}{l}\text { Change } S \\
\text { F Change }\end{array}$ & $\begin{array}{l}\text { tatis } \\
\text { df1 }\end{array}$ & $\begin{array}{l}\text { es } \\
\text { df } 2\end{array}$ & \\
\hline 1 & $.653 a$ & .426 & .424 & .30359 & .557 & 399.829 & 1 & 418 & .000 \\
\hline 2 & $.786 \mathrm{~b}$ & .619 & .616 & .24783 & .077 & 67.173 & 1 & 317 & .000 \\
\hline 3 & $.810 c$ & .656 & .652 & .23586 & .021 & 19.425 & 1 & 316 & .000 \\
\hline
\end{tabular}

a. Predictors: (Constant), Kemahiran

b.Predictors: (Constant), Kemahiran, Sikap

c. Predictors: (Constant), Kemahiran, Sikap, Pengetahuan

d.Dependent Variable: Pencapaian Kendiri Guru

Hasil analisis seperti dalam Jadual 2 menunjukkan korelasi kesemua tiga pemboleh ubah peramal Sikap Guru Bahasa Melayu, Pengetahuan Guru Bahasa Melayu dan Kemahiran Guru Bahasa Melayu, dengan pemboleh ubah criterion Pencapaian Kendiri Guru Bahasa Melayu adalah tinggi (Model 1. $r=653$, model $2 \mathrm{r}=786$, model 3, r=810). Berdasarkan analisis (Model 3) gabungan kesemua tiga pemboleh ubah peramal mempunyai korelasi yang paling tinggi dengan pemboleh ubah criterion $\mathrm{KP}(\mathrm{r}=810)$. Analisis ini dapat dibuktikan melalui jadual 2 dalam ujian ANOVA yang mana model 3 mempunyai nilai $\mathrm{F}=$ 200.535 signifikan pada $\mathrm{p}<0.00$.

Jadual 3: Analisis Ujian ANOVA Pemboleh Ubah Peramal Kajian

\begin{tabular}{llllll}
\hline \multicolumn{1}{l}{ ANOVA $^{\text {a }}$} & & & & \\
\hline Model & Sum of Squares & df & Mean Square & F & Sig. \\
\hline 3. Regression & 33.467 & 3 & 11.156 & 200.535 & $.000^{d}$ \\
Residual & 17.579 & 316 & .056 & & \\
Total & 51.046 & 319 & & & \\
\hline
\end{tabular}

a. Dependent Variable: Pencapaian Kendiri Guru Bahasa Melayu

b.Predictors: (Constant), Sikap

c. Predictors: (Constant), Sikap, Pengetahuan

d.Predictors: (Constant), Sikap, Pengetahuan, Kemahiran

Jadual 3 menunjukkan peratusan pengaruh semua tiga pemboleh ubah peramal terhadap pemboleh ubah criterion Pencapaian Kendiri Guru Bahasa Melayu Sekolah Kebangsaan. Nilai kombinasi kesemua pemboleh ubah peramal R2 $=0.810, \mathrm{p}=0.00(\mathrm{p}<0.05)$ model 3 yang menyumbang penyebab kepada perubahan criterion.

Jadual 4 menunjukkan sumbangan pemboleh ubah peramal kepada pemboleh ubah criterion. Berdasarkan nilai Standardized Coefficients (Beta) pemboleh ubah Sikap $(B=0.275)$ merupakan peramal yang lebih baik terhadap pemboleh ubah bersandar Pencapaian Kendiri Guru Bahasa Melayu berbanding Pengetahuan $(B=0.206)$ dan Kemahiran $(B=0.270)$ yang mana kesimpulan di buat pada aras signifikan $0.00(\mathrm{p}<0.05)$ atau tahap keyakinan 95 peratus. 
Jadual 4: Analisis Pengaruh Coefficients Beta Pemboleh Ubah Peramal Terhadap Pemboleh Ubah Criterion

\begin{tabular}{|c|c|c|c|c|c|c|c|}
\hline \multirow{3}{*}{ Model } & & & \multicolumn{5}{|l|}{ Coefficients } \\
\hline & \multicolumn{2}{|c|}{$\begin{array}{l}\text { Unstandardized } \\
\text { Coefficients }\end{array}$} & \multirow{2}{*}{$\begin{array}{c}\text { Standardized } \\
\text { Coefficients } \\
\text { Beta }\end{array}$} & \multirow[b]{2}{*}{$\mathbf{t}$} & \multirow{2}{*}{ Sig. } & \multicolumn{2}{|c|}{$\begin{array}{l}\text { 95.0\% Confidence } \\
\text { Interval for B }\end{array}$} \\
\hline & B & $\begin{array}{l}\text { Std. } \\
\text { Error }\end{array}$ & & & & $\begin{array}{l}\text { Lower } \\
\text { Bound }\end{array}$ & $\begin{array}{l}\text { Lower } \\
\text { Bound }\end{array}$ \\
\hline 3 (Constant) & .959 & .129 & & 7.407 & .000 & .212 & .907 \\
\hline Sikap & .275 & .039 & .291 & 7.032 & .000 & .347 & .510 \\
\hline Pengetahuan & .206 & .047 & .272 & 4.407 & .000 & .154 & .247 \\
\hline Kemahiran & .270 & .046 & .354 & 5.831 & .000 & .182 & .359 \\
\hline
\end{tabular}

a. Dependent Variable: Pencapaian Kendiri Guru

\section{Perbincangan Kajian}

Berdasarkan pengaruh antara pemboleh ubah yang terdiri daripada pengetahuan dan kemahiran guru Bahasa Melayu dengan pencapaian kendiri guru Bahasa Melayu. Hasil menunjukkan ketiga-tiga pemboleh ubah menyumbang kepada perubahan variable criterion terhadap Pencapaian Kendiri Guru Bahasa Melayu Sekolah Kebangsaan di Sabah apabila pemboleh ubah digabungkan. Berdasarkan analisis gabungan kesemua tiga pemboleh ubah peramal mempunyai korelasi yang paling tinggi dengan pemboleh ubah criterion Pencapaian Kendiri Guru Bahasa Melayu. Pemboleh ubah peramal Sikap Guru Bahasa Melayu, Pengetahuan Guru Bahasa Melayu dan Kemahiran Guru Bahasa Melayu dapat menjelaskan 81 peratus daripada varians dalam pemboleh ubah criterion Pencapaian Kendiri Guru Bahasa Melayu di Sekolah. Manakala selebihnya 19 peratus Pencapaian Kendiri Guru Bahasa Melayu di sekolah ditentukan oleh faktor-faktor lain yang tidak dikaji dalam penyelidikan ini. Terdapat bukti yang kukuh untuk menolak hipotesis nol dan kesimpulan menunjukkan pemboleh ubah peramal sikap, Pengetahuan dan Kemahiran merupakan peramal yang signifikan menentukan pencapaian kendiri guru bahasa Melayu Sekolah Kebangsaan di negeri Sabah.

\section{Kesimpulan}

Daripada dapatan-dapatan melalui tinjauan literatur yang dijalankan, penguasaan pencapaian kendiri ini sangat penting dalam memastikan kecemerlangan pendidikan murid-murid dalam aspek akademik di sekolah. Guru-guru Bahasa Melayu perlu menguasai konsep kendiri dalam pengajaran dan pembelajaran. Selain itu, guru-guru perlu mentransformasikan pemikiran agar dapat menukar paradigma bahawa pencapaian seseorang guru itu bukan dinilai dari segi gred semata-mata, untuk melahirkan guru Bahasa Melayu yang seimbang dan harmonis di samping pentadbir juga memainkan peranan dalam memberi motivasi kepada guru-guru dalam perubahan pendidikan yang semakin melonjak naik dan pencapaian perlu dipertingkatkan dan perlu penambahbaikan mengikut keperluan semasa dalam penguasaan konsep kendiri yang baik dalam kalangan guru-guru Bahasa Melayu.

\section{Rujukan}

Adriana Muhamad Akhir, Muhamad Suhaimi Taat, Syahrul Nizam Salam. (2020). Hubungan Sikap, Kesediaan Guru Dan Efikasi-Kendiri Guru Dengan Komuniti pembelajaran Profesional. International Journal of Education, Psychology and Counseling, 5(37), 221-231.

Ahmad Mahzan Ayub. (1995). Kaedah Penyelidikan Sosioekonomi. Kuala Lumpur: Dewan Bahasa dan Pustaka 
Bandura, A., \& Adams, N. E. (1977). Analysis of self-efficacy theory of behavioral change. Cognitive therapy and research, $1(4), 287-310$.

Bandura, A. (1997). Social learning theory. Englewood Cliffs, NJ: Prentice Hall

Chua, Y. P. (2006). Kaedah dan Statistik Penyelidikan: Kaedah Penyelidikan, Malaysia. McGrawHillEducation

Chua, Y.P. (2005). Kaedah dan Statistik penyelidikan. McGrraw-Hill Education, Malaysia.

Cohen, Mahon \& Morrison (2000). Research Methods in education. London: RouteledgeFalmer,

Gazali \& Sufean (2016). Metodologi penyelidikan dalam pendidikan: Amalan dan analisis kajian. Penerbit Universiti Malaya.

Klapp, A. (2018). Does academic and social self-concept and motivation explain the effect of grading on students' achievement?. European Journal of Psychology of Education, 33(2), 355-376.

Lunenburg, F. C. \& Ornstein, A. C. (2008). Educational administration: Concepts and practices. Fifth ed. Belmont, CA: Thomson Books/Cole.

Mohd Hussin Musa, Christina Andin \& Syahrul Nizam Salam. (2020). Kesahan Dan Kebolehpercayaan Instrumen Pentaksiran Kemahiran Insaniah Murid (IPKIM) Mata Pelajaran Rekacipta. International Journal of Education, Psychology and Counseling, 5(37), 96-107.

Norin Farizah Mohd Nuin, Abdul Said Ambotang, \& Syahrul Nizam Salam. (2020) Pengaruh motivasi dan kompetensi terhadap perubahan pengurusan data murid di Sabah. International Journal of Education, Psychology and Counselling, 5(34), 116-125.

Osman Said, Mohd. Nasir Rayung, Syahrul Nizam Salam \& Abdul Said Ambotang. (2020). Pengaruh Sikap Guru, Pengetahuan Guru dan Kemahiran Guru Terhadap Kompetensi Pengurusan Disiplin Sekolah Kebangsaan di Sabah. International Journal of Education, Psychology and Counseling, 5 (35), 188-205.

Kementerian Pendidikan Malaysia. (2013). Pelan Pembangunan Pendidikan Malaysia 2013-2015. Putrajaya: Kementerian Pendidikan Malaysia.

Ravichandran, R., \& Rajendran, R. (2007). Perceived sources of stress among the teachers. Journal of the Indian Academy of Applied Psychology, 33(1), 133-136.

Syahrul Nizam Salam, Abdul Said Ambotang, Ghazali Hassan Sulaiman. (2018). Pengaruh Faktor Penyumbang Terhadap Kendiri Pelajar Ekonomi Tingkatan Enam Di Sabah. Jurnal Penyelidikan Akademik, Institut Pendidikan Guru Malaysia, Kementerian Pendidikan Malaysia, 3(34), 34-51.

Syahrul Nizam Salam, Abdul Said Ambotang, Ghazali Hassan Sulaiman. (2019). Hubungan Sikap Terhadap Ekonomi Dan Kefahaman Konsep Ekonomi Dengan Kendiri Pelajar Ekonomi. Jurnal Kurikulum, Bahagian Pembangunan Kurikulum, Kementerian Pendidikan Malaysia, 4(34), 16-29.

Soulé, H., \& Warrick, T. (2015). Defining 21st century readiness for all students: What we know and how to get there. Psychology of Aesthetics, Creativity, and the Arts, 9(2), 178.

van Rooij, E. C. M., Fokkens-Bruinsma, M., \& Goedhart, M. (2019). Preparing science undergraduates for a teaching career: Sources of their teacher self-efficacy. The Teacher Educator, 54(3), 270-294.

van Rooij, E. C., Jansen, E. P., dan van de Grift, W. J. (2017). Factors that contribute to secondary school students' self-efficacy in being a successful university student. Research in PostCompulsory Education, 22(4), 535-555. 